\title{
РЕАКЦИОННО-ГАЗОХРОМАТОГРАФИЧЕСКИЙ АНАЛИЗ ОРГАНИЧЕСКОГО ВЕЩЕСТВА ГОРЮЧИХ СЛАНЦЕВ МЕТОДАМИ ДЕСОРБЦИИ И ПИРОЛИЗА
}

\author{
(Представил О. Эйзен)
}

Обычно ископаемое органическое вещество (ОВ) характеризуют косвенно - по выходу смолы полукоксования и ее составу или по выходу экстрактов, получаемых из твердых осадков, и степени их битуминозности, или же по углеводородному коэффициенту. Вышеназванные способы требуют значительного количества исходного матернала, сопровождаются потерями легких компонентов, а получаемые продукты зачастую вторичны.

Прямое газохроматографическое определение газообразных, жидких и твердых углеводородов, улетучивающихся из горючего сланца при его нагревании до $280^{\circ} \mathrm{C}$ в испарителе хроматографа в токе водяного пара, проведено на силиконовых неподвижных фазах $\left[{ }^{1}\right]$. Пиролитическим методам в сочетании с газовой хроматографией - пирохроматографии, употребляемой для установления структуры самых разных веществ, посвящено большое количество работ, например $\left[{ }^{2}\right]$. Применение газовой хроматографии позволяет исследовать состав летучих соединений битумоида и продуктов пиролиза керогена на молекулярном уровне. Моди-

Таблица 1

Некоторые данные анализируемых твердых топлив

\begin{tabular}{|c|c|c|c|c|c|c|}
\hline \multirow{2}{*}{ Твердое топливо и месторождение } & \multirow{2}{*}{ 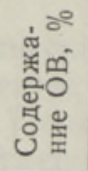 } & \multicolumn{3}{|c|}{$\begin{array}{c}\text { Содержание биту- } \\
\text { мондов, \% }\end{array}$} & \multirow{2}{*}{$\begin{array}{c}\text { Пернод обра- } \\
\text { зования }\end{array}$} & \multirow{2}{*}{ 哭 } \\
\hline & & A & C & $A+C$ & & \\
\hline \multicolumn{7}{|l|}{ Горючие сланцы: } \\
\hline $\begin{array}{l}\text { Чаганск, Оренбургская обл. } \\
\text { Кендерлык, Казахская ССР } \\
\text { Менилит, Карпаты } \\
\text { Кукерсит, Кивиыли } \\
\text { Боров Дол, Болгария } \\
\text { Грин-Ривер, США } \\
\text { Кукерсит 90 }\end{array}$ & $\begin{array}{r}56,7 \\
48,4 \\
19,9 \\
47,6 \\
22,0 \\
29,2 \\
-\end{array}$ & $\begin{array}{l}1,1 \\
2,9 \\
1,9 \\
\overline{2,1} \\
-\end{array}$ & $\begin{array}{l}0,8 \\
4,0 \\
3,2 \\
\overline{5,2} \\
-\end{array}$ & $\begin{array}{l}1,9 \\
6,9 \\
5,1 \\
0,7 \\
7,3 \\
3,0 \\
-\end{array}$ & $\begin{array}{l}\text { Верхняя юра } \\
\text { Карбон-пермь } \\
\text { Палеоген } \\
\text { Ордовик } \\
\text { Эоцен } \\
\text { Эоцен } \\
\text { Ордовик }\end{array}$ & $\begin{array}{l}3 \\
{[4]} \\
5 \\
5 \\
6] \\
{[7]}\end{array}$ \\
\hline \multicolumn{7}{|l|}{ Другие топлива: } \\
\hline $\begin{array}{l}\text { Балхашит, оз. Балхаш } \\
\text { Витринит, Кузнецкий бассейн } \\
\text { Сапропелит, Будагово, Иркутская } \\
\text { обл. } \\
\text { Богхед, Болгария, Боров Дол } \\
\text { Липтобиолит, Липовецк, Примор- } \\
\text { ский край } \\
\text { Липтобнолит, Ткибули, Грузин- } \\
\text { ская ССР }\end{array}$ & $\begin{array}{l}94,0 \\
94,2 \\
90,2 \\
48,3 \\
43,7 \\
84,8\end{array}$ & $\begin{array}{l}8,1 \\
0,6 \\
\overline{2,9} \\
1,0 \\
-\end{array}$ & $\begin{array}{l}5,4 \\
3,4 \\
\overline{2,5} \\
0,6 \\
-\end{array}$ & $\begin{array}{r}13,5 \\
4,0 \\
3,6 \\
5,4 \\
1,6 \\
7,5\end{array}$ & $\begin{array}{l}\text { Современный } \\
\text { Юра } \\
\text { Эоцен } \\
\text { Ннжний мел } \\
\text { Юра }\end{array}$ & $\begin{array}{l}{\left[{ }^{8}\right]} \\
{[9]} \\
{\left[{ }^{10}\right]}\end{array}$ \\
\hline
\end{tabular}




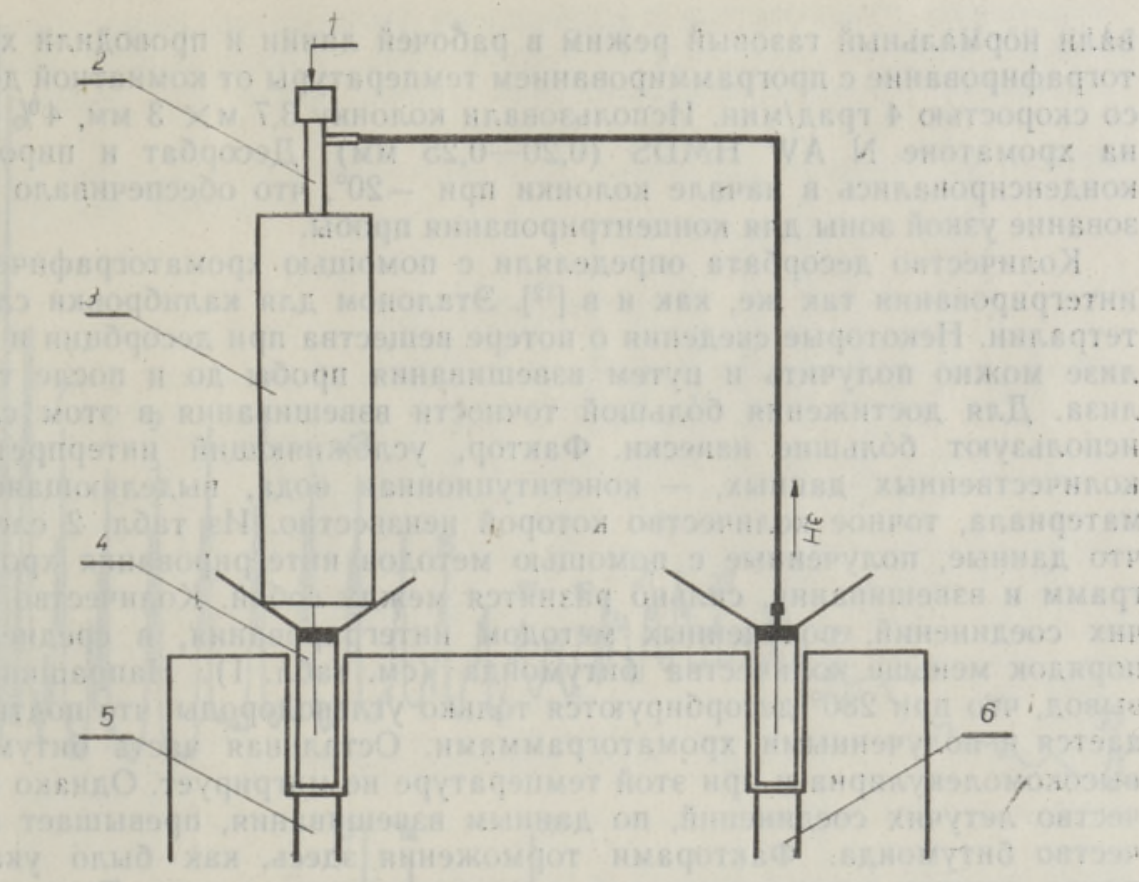

Рнс, 1. Схема присоединения реактора к хроматографу. 1 -ввод пробы; 2 - стеклянная трубка; 3 - трубчатая печь; 4 - испаритель хроматографа; 5 - рабочая колонка; 6 - колонка сравнения.

фицированный вариант пирохроматографии был использован также в настоящей работе. Представленные в табл. 1 виды твердого топлива, служившие в качестве образцов при исследовании, были предварительно проанализированы с помощью других методов.

В настоящей работе исходный материал (горючие сланцы, угли, сапропелиты) подвергали двухэтапному термолизу: 1) десорбции летучих соединений при температуре $280^{\circ}$, предшествующей началу активного разложения $\mathrm{OB} ; 2$ ) деструктивному разложению керогена - пиролизу при $450^{\circ}$. Использовали автономный реактор (стеклянная трубка длиной 160 мм и внутренним диаметром 4 мм), находящийся в вертикальном обогреваемом кожухе. Порошок в гильзе (трубка $80 \times 2$ мм) опускали в нагретый до определенной температуры реактор. Пробу (для десорбции $\sim 100$ мг, для пиролиза - не более 5 мг) помещали в гильзе между двумя пробками из тонкой нержавеющей стали. Другой возможный материал для пробок (стеклянная вата) обычно загрязнен, и его очистка с помощью низкокипящих растворителей почти невозможна. Продолжительность выдержки образца при установленной температуре в обеих стадиях термической обработки составляла 10 мин, причем для пиролиза брали десорбированную пробу.

Пробу вводили в реактор, соединенный с обоими испарителями хроматографа с помощью инъекционных игл, как показано на рис. 1. Это способствовало созданию нужного потока газа-носителя для транспортировки летучих соединений из зоны реакции в рабочую колонку. Газомносителем как во время десорбции и пиролиза, так и во время хроматографирования служил гелий. В момент введения продуктов термолиза в анализатор прекращали подачу гелия в рабочую колонку и газ для продувания реактора поступал через испаритель колонки сравнения. Продукты термической обработки направлялись прямо в хроматограф «Хром-41», после чего реактор отключали от хроматографа, устанавли- 
валй нормальный газовый режим в раб́очей линйи й проводиилй хрома̀тографирование с программированием температуры от комнатной до $320^{\circ}$ со скоростью 4 град/мин. Использовали колонку 3,7 м $\times 3$ мм, $4 \%$ Е 301 на хроматоне $\mathrm{N}$ AW HMDS $(0,20-0,25$ мм). Десорбат и пиролизат конденсировались в начале колонки при $-20^{\circ}$, что обеспечивало образование узкой зоны для концентрирования пробы.

Количество десорбата определяли с помощью хроматографического интегрирования так же, как и в $\left.{ }^{12}\right]$. Эталоном для калибровки служил тетралин. Некоторые сведения о потере вещества при десорбции и пиролизе можно получить и путем взвешивания пробы до и после термолиза. Для достижения бо́льшой точности взвешивания в этом случае используют бо́льшие навески. Фактор, усложняющий интерпретацию количественных данных, - конституционная вода, выделяющаяся из материала, точное количество которой неизвестно. Из табл. 2 следует, что данные, полученные с помощью методов интегрирования хроматограмм и взвешивания, сильно разнятся между собой. Количество летучих соединений, полученных методом интегрирования, в среднем на порядок меньше количества битумоида (см. табл. 1). Напрашивается вывод, что при $280^{\circ}$ десорбируются только углеводороды, что подтверждается и полученными хроматограммами. Остальная часть битумоида высокомолекулярна и при этой температуре не мигрирует. Однако количество летучих соединений, по данным взвешивания, превышает количество битумоида. Факторами торможения здесь, как было указано ранее, служат гигроскопическая и конституционная вода. Таким образом, применяя метод интегрирования, можно получить данные о содержании летучих углеводородов в топливе.

Основные продукты обеих стадий термолиза - нормальные парафины, но присутствуют также изопреноидные и ароматические углеводороды. Углеводороды $\leqslant \mathrm{C}_{5}$ не разделялись, хотя для их концентрации в начале колонки применяли охлаждение. Это явление может быть обусловлено также специфическими свойствами колонки и свойствами неподвижной фазы.

Будаговский каустобиолит (рис. 2) содержит мало низкокипящих углеводородов, зато много изопреноидов. Основные компоненты пиролизата - $H$-углеводороды, имеющие довольно длинные углеводородные цепи (до $\mathrm{C}_{33}$ ). Характерная особенность хроматограммы - наличие пиков кетонов. Кендерлыкский горючий сланец [4] (рис. 3) содержит низкокипящие соединения, большое количество различных углево-

таблица 2

\section{Летучие соединения (\% от ОВ) при $280^{\circ} \mathrm{C}$ по данным} интегрирования и взвешивания

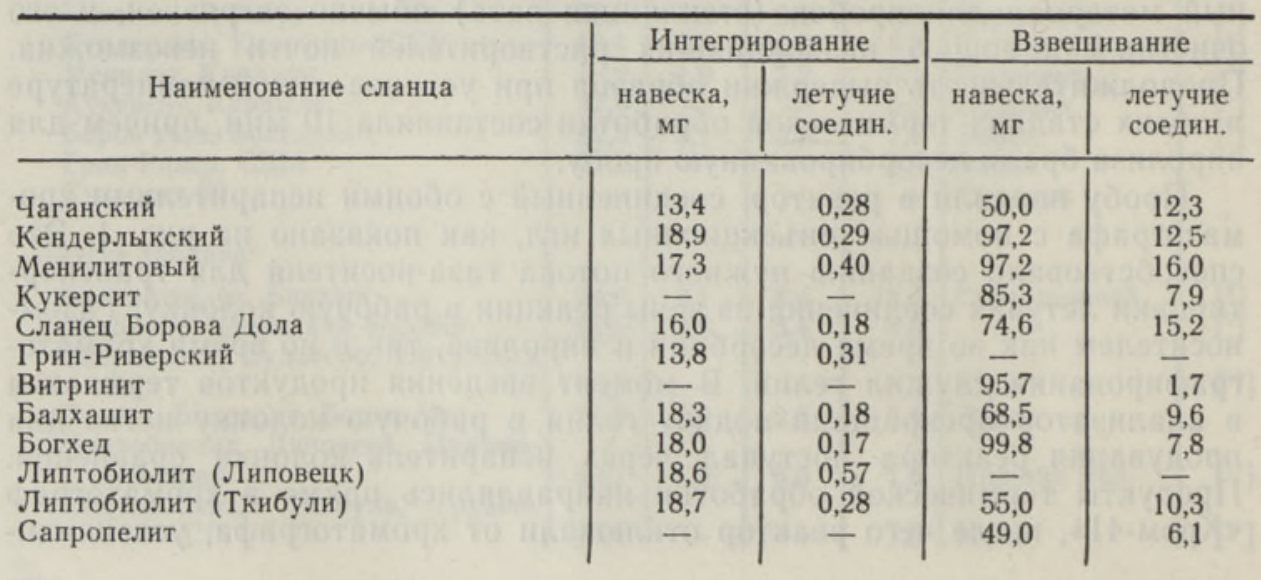




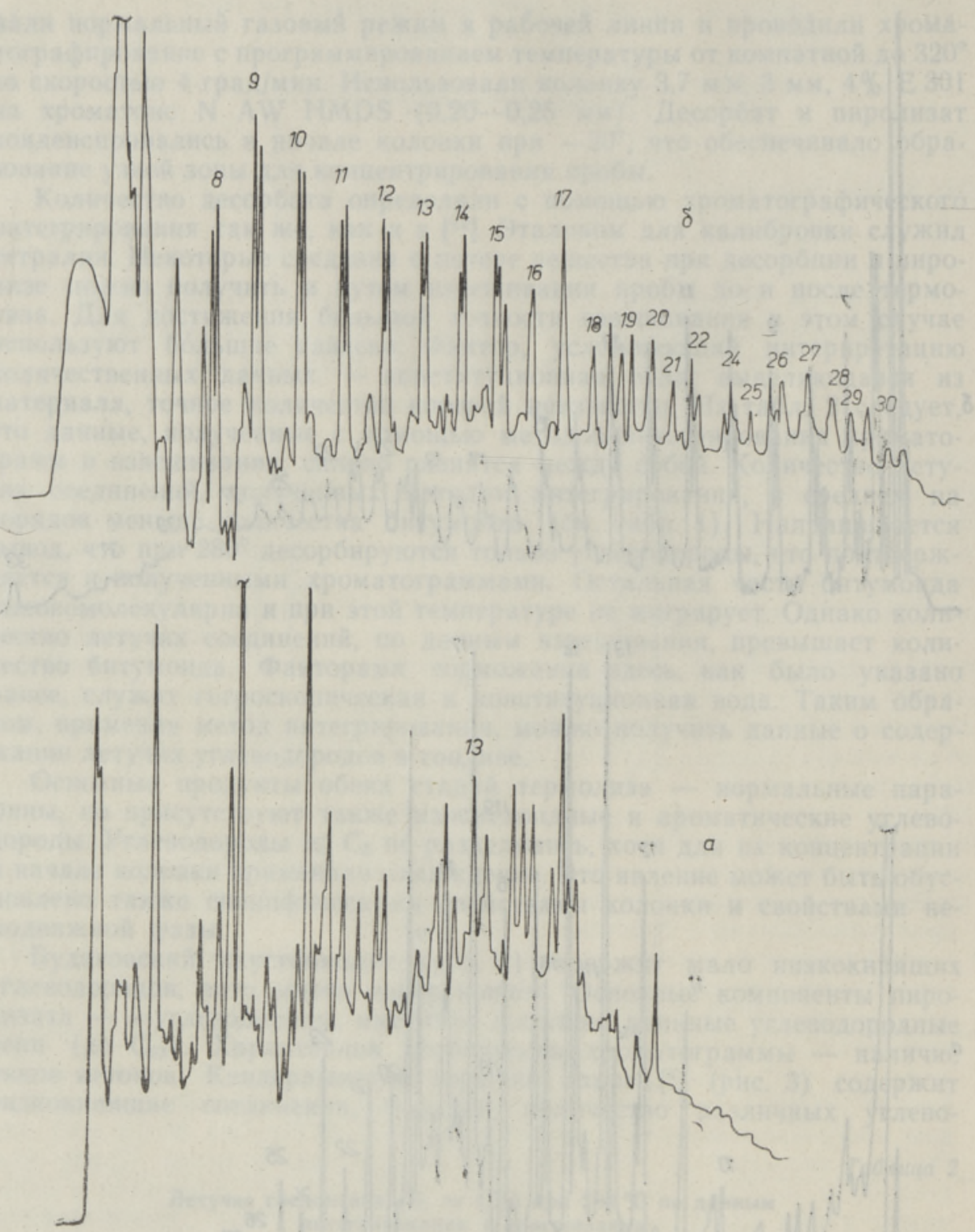

Рис. 3. Хроматограммы десорбата (a) и пиролизата (б) кендерлыкского горючего сланца. Навески проб соответственно 92,7 и 5 мг. Цифры над пиками указывают на число атомов углерода в цепи $H$-парафннов.

также различаются. В обоих продуктах всегда присутствуют $\boldsymbol{H}$-парафины, но их количественное распределение различное. В десорбатах часто присутствуют изопреновые углеводороды, в пиролизатах - обязательно олефины.

На основании проведенных исследований можно заключить, что при длительных (порядка 10 мин) процессах десорбции и пиролиза при относительно низкой температуре их продукты правильно отражают структуру керогена. Состав десорбатов похож на состав углеводородов битумоидов, выделенных экстрагированием, пирограммы отвечают хроматограммам суммарных смол, получаемых лабораторным полукоксованием по Фишеру. Метод позволяет быстро оценивать исследуемые образцы. 
Быстрота анализа, легкость его выполнения и достаточность микроколичеств исследуемых проб - несомненные преимущества метода. Однако не исключено, что проба может оказаться недостаточно представительной.

Автор выражает благодарность И. Р. Клесменту за просмотр работы и критические замечания.

\section{Л ИТЕРАТУ Р А}

1. Клесмент И., Талвари А. Десорбция углеводородов в испарителе хроматографа под воздействнем паров воды. - Геол. нефти и газа, 1976, № 9, 49-54.

2. Analytical Pyrolysis. Amsterdam, 1977.

3. Клесмент Н., Побуль Л., Куузик М. Характеристика битумондов горючего сланща чаганского месторождения Оренбургской области. - Изв. АН ЭССР, Хим., 1981, 30, № 3, 187-193.

4. Побуль Л., Клесмент И., Куузик М. Исследование органического вещества кендерлыкских горючих сланцев, - Изв. АН ЭССР, Хим., 1982, 31, № 1, 25-32.

5. Побуль Л., Клесмент Н., Куузик М. Исследование состава и генезиса карпатских менилитовых сланцев. - Изв. АН ЭССР, Хим., 1981, 30, № 4, 259-266.

6. Пайс Р., Клесмент И., Побуль Л. Углеводороды и кислородные соединения в битумоиде сланца-кукерсита. - Изв. АН ЭССР, Хим., 1979, 28, № 3, 182-190.

7. Клесмент Н., Куузик М., Побуль Л. Битуминологическая характеристика болгарского горючего сланца месторождения Боров Дол. - Изв. АН ЭССР, Хим., 1981, 30, № 2, 69-74.

8. Побуль Л., Клесмент Н. Исследование балхашита. - Изв. АН ӘССР, Хим., 1981, 30, № 2, 75-83.

9. Клесмент Н., Уров К., Куузик М., Высоцкая В. Характеристика битумонда и смолы полукоксования витринитового каменного угля Кузбасса. - Изв. АН ЭССР, Хим., 1980, 29, № 2, 77-83.

10. Шиверская И., Клесмент И., Уров К., Урмет Э. Состав органического вещества будаговских сапропелитов. - В кн.: Синтез высокомолекулярных продуктов на основе сапропелитов и кремнийорганических соединений. Иркутск, 1976, 17-31.

11. Клесмент И., Куузик М. Состав битумоидов и вопросы генезиса липтобиолитовых углей. - Хим. тверд. топл., 1981, № 2, 17-25.

12. Клесмент И., Салусте С., Луйк Х. Использование имитированной дистиллящии для определения фракционного состава сланцевых смол. - Изв. АН ЭССР, Хим., 1981,30 , № $1,5-9$.

\section{Ннститут химии \\ Академии наук Эстонской ССР}

Поступила в редакцию 29/VI 1982

\section{H. LUIK}

\section{POLEVKIVI ORGAANILISE AINE REAKTSIOONI-GAASIKROMATOGRAAFILINE ANALUUS DESORBTSIOONI- JA PUROLOUSIMEETODIL}

Artiklis kirjeldatud analüüsiskeem võimaldab tahkekütuste orgaanilise aine koostist kiiresti iseloomustada. 13 uuritud proovi kromatogrammid peegeldavad õigesti vastava kerogeeni struktuuri.

\section{H. $L U T K$}

\section{REACTION-GAS-CHROMATOGRAPHIC TECHNIQUE FOR THE ANALYSIS OF ORGANIC MATTER IN OIL SHALES BY DESORPTION AND PYROLYSIS METHODS}

A simple microreactor-gas-chromatographic technique for the rapid characterization of solid fuels is described. Thirteen samples were investigated. $n$-paraffins, isoprenoids and aromatic compounds are the basic products of thermolysis; isoprenoids occur more frequently as components of desorption. Pyrolysis products always contain $n$-olefines. The chromatograms reflect the structure of kerogen adequately. 